(2) OPEN ACCESS

\title{
Corporate communication of the relative health risks of IQOS through a webchat service
}

\author{
Sophie Braznell 자, ${ }^{1}$ J Robert Branston 다, ${ }^{2}$ Anna B Gilmore ${ }^{1}$
}

- Additional supplemental material is published online only. To view, please visit the journal online (http://dx.doi. org/10.1136/tobaccocontrol2021-056999).

'Department for Health, University of Bath, Bath, UK ${ }^{2}$ School of Management, University of Bath, Bath, UK

Correspondence to Sophie Braznell, Department for Health, University of Bath, Bath, UK; seb91@bath.ac.uk

Received 23 August 2021 Accepted 31 January 2022
D) Check for updates

(C) Author(s) (or their employer(s)) 2022. Re-use permitted under CC BY-NC. No commercial re-use. See rights and permissions. Published by BMJ.

To cite: Braznell $S$, Branston JR, Gilmore AB. Tob Control Epub ahead of print: [please include Day Month Year]. doi:10.1136/ tobaccocontrol-2021-056999

\section{ABSTRACT}

Background Communication of the relative health risks of IQOS can attract potential consumers, aiding its commercial success. However, health-related claims need to be used cautiously to avoid inaccuracies and attracting non-smokers. We used the live webchat service on the IQOS website to identify information and claims on the relative risks of IQOS made directly to potential consumers in different countries.

Methods The study was promoted through authors' networks and conducted between 1 August and 30 November 2020. Participants collected webchat conversation responses to three queries regarding the safety of IQOS relative to cigarettes and e-cigarettes using step-by-step guidance and a predesigned form. Responses were analysed to identify health-related claims and information provided.

Results 70 webchat attempts were recorded across 27 countries, 54 of which (in 22 countries) were successful webchat conversations. In 48 of these, one or more claims were used to indicate IQOS is safer than cigarettes, such as IQOS is smoke free, emits less harmful substances or reduces harm. Four conversations contained statements indicating IQOS is safer than ecigarettes. Some statements provided were contradictory. Participant age was consistently requested on accessing the website, but tobacco/nicotine use was not. Other information provided included referral to the 2020 US Food and Drug Administration Modified Risk Tobacco Product decision, IQOS or Philip Morris International web pages and claims that IQOS is not risk free nor a cessation device.

Conclusions A variety of claims and information on the relative safety of IQOS were used in webchat communications. Response variation highlights that clearer regulation is needed to appropriately control corporate communications via live webchat services.

\section{INTRODUCTION}

IQOS is Philip Morris International's (PMI) flagship non-conventional tobacco product brand. It is the international heated tobacco product (HTP) market leader, officially sold in 64 countries at the end of 2020. ${ }^{12}$ PMI uses claims that IQOS reduces health risks compared with cigarettes to promote IQOS $^{3}$ and aid its commercial success. ${ }^{4-6}$ While these claims can attract smokers looking to reduce the adverse effects of smoking, ${ }^{7}$ caution is needed so as to not overstep the evidence and to avoid ex-smoker and non-smoker uptake. Indeed, there is evidence that some claims could mislead consumers about the risks of IQOS; for example, conflation between reduced risk and risk free, ${ }^{8}$ reduced exposure and reduced harm, ${ }^{9}{ }^{10}$ and a $95 \%$ reduction in harm and a 5\% risk of harm. ${ }^{11}$ Moreover, the scientific evidence behind some of PMI's claims remains contentious: much of the primary research on IQOS has been conducted and/or funded by PMI, ${ }^{12} 13$ and although there is evidence of reduced exposure to harmful substances relative to cigarettes, there is insufficient evidence to show this leads to reduced harm or tobacco-related disease. ${ }^{14}$

Communicating its science and the potential benefits of IQOS through one-to-one consumer engagement is a key element in PMI's promotion of IQOS. $^{2}{ }^{15}$ As interest in buying and selling tobacco and nicotine products online has grown, ${ }^{16} \mathrm{PMI}$ is increasingly using e-commerce models, such as the online IQOS store, ${ }^{17}$ to market IQOS and engage with consumers, particularly through the COVID-19 pandemic. $^{2}$ On the IQOS online store, PMI offers a live webchat support service through which they can digitally converse with consumers in real time. ${ }^{17}$ Use of such live webchats by consumers, which can increase satisfaction and purchases, ${ }^{18}$ is growing in many different industries. ${ }^{19}$ To our knowledge, this form of marketing has not previously been explored in tobacco product research beyond identifying its presence on company websites. ${ }^{20}$

The regulatory landscape for HTPs is complex due to their design and the contentious nature of existing evidence, ${ }^{21}$ and the accelerated expansion of digital marketing presents further challenges to regulating the promotion of products like IQOS. ${ }^{16}{ }^{22}$ We observed the impact of regulation variation when we (in the UK) and a public health colleague in the USA received different responses after asking about the relative risks of IQOS through the webchat service on our respective domestic IQOS websites. In the UK we were told IQOS was 'up to $95 \%$ safer than cigarettes' (22 April 2020), whereas our colleague in the USA was told that claims relating to health could not be made, likely because PMI did not have permission to make such claims in the USA at the time. ${ }^{23}$

As seen in the UK webchat interaction, claims on the relative risks of IQOS are often based on its comparison with cigarettes. ${ }^{3}$ However, there is increasing research on the relative risks of IQOS compared with e-cigarettes. Some studies have found IQOS increases exposure to some toxicants ${ }^{24-27}$ and is more cytotoxic than e-cigarettes. ${ }^{28}$ Clinical evidence suggests IQOS may be equally less harmful to health ${ }^{29}$ but is more satisfying than e-cigarettes. ${ }^{24}{ }^{29}$ We therefore sought to investigate our earlier observations further by identifying claims made to potential consumers regarding the health risks of IQOS relative to cigarettes and e-cigarettes, and whether such claims varied between different countries. 


\section{METHODS}

PMI's live IQOS webchat service offered an easily accessible route to simultaneously collect relevant data from numerous countries, especially during the contemporary COVID-19 restrictions. Moreover, it allowed targeted collection of claims regarding the relative safety of IQOS compared with e-cigarettes, which do not ordinarily appear in IQOS advertising.

Data collection was conducted from 1 August to 30 November 2020. The authors promoted the study through academic and tobacco control advocate networks via digital communication channels and word of mouth. The authors provided potential participants with an information sheet explaining the study, a guide on data collection and the data collection form. Participants were eligible if they were over 18 years old, were situated in one of the 57 countries where IQOS was officially marketed at the time, ${ }^{30}$ had access to an internet-connected device and could competently read and write in English. Participants were not compensated. We aimed for at least two responses from each country to avoid making inferences based on potentially rogue conversations while remaining realistic given the restrictive recruitment strategy.

Following a step-by-step guide, participants were instructed to initiate a conversation through the webchat on the domestic IQOS website and ask three questions: (1) is IQOS safer than cigarettes; (2) is IQOS safer than e-cigarettes; and (3) how much safer is IQOS than (cigarettes and e-cigarettes)? As questions were to be asked multiple times and in various languages, participants were permitted to adapt their conversation approach including asking the questions in any order and using colloquial terminology, such as 'vaping'.

Using a predesigned electronic form, participants recorded contextual details for example, date and time, country, language, URL and information requested in order to access the website, as well as a transcript of their conversation copied from the webchat. Although not mandatory, all participants translated their own conversation transcripts that were in other languages into English. Both participants and IQOS webchat operators were anonymised. All participants provided consent; however, consent was not obtained from webchat operators because it was not known whether the webchat operators were human beings or chatbots, and it would have been impossible to obtain consent without informing IQOS staff of the study, which could have changed their responses.

Given the small sample size and brevity of the conversations, responses were analysed and coded by SB using Microsoft Excel. Codes were developed inductively. First, any statements made on the relative risks of IQOS versus cigarettes or e-cigarettes were identified. As observed in the UK webchat interaction, harm reduction claims used in IQOS marketing sometimes include a quantitative figure. ${ }^{3}$ Therefore, statements categorised as 'IQOS reduces harm or risk compared to cigarettes' or 'IQOS emits less harmful substances compared to cigarettes' were further coded based on whether they included a quantification of the relative safety of IQOS. Once the codes were developed, each conversation was coded for the presence or absence of each code. In addition, conversations were coded for mentions of the US Food and Drug Administration (FDA) Modified Risk Tobacco Product (MRTP) decision, reference to another PMI or IQOS website, instances where IQOS was called a reduced risk product and statements that research on IQOS was ongoing and that definitive conclusions on its reduced risk status could not be made. All codes and their descriptions are provided in online supplemental table 1. Descriptive statistics were calculated in IBM SPSS V.27. Standard ISO alpha-2 abbreviation codes for countries $^{31}$ are used throughout the text.

\section{RESULTS}

Seventy completed forms detailing attempted webchat conversations were collected from participants in 27 of the 57 target countries (table 1). Most participant submissions contained one form, suggesting webchat attempts were typically conducted by different individuals, rather than one individual completing multiple attempts, although this cannot be confirmed since forms were anonymous and multiple forms in one submission may have been from a group of colleagues submitting through one individual. Despite advertising across all regions, no completed forms were received from 30 countries. There was no webchat on the IQOS websites in Armenia, Israel, Serbia and Ukraine. One participant in the Republic of Korea (South Korea) ceased engagement after being asked to provide extensive personal details at the start of the conversation. In two of the three webchat attempts in France, participants received no response from webchat operators. This was also the case in two of three webchat attempts in Canada. While one successful webchat was collected in the USA in mid-September, in late-September, the webchat was not available due to website maintenance (which the author team found to be the case until the end of the study period). Therefore, there were 54 successful webchat conversations across 22 countries.

In Denmark, Italy, Lebanon, Lithuania, Poland and The Netherlands, at least one webchat conversation was conducted in a non-native language, namely English (table 1 ). In the USA, the IQOS website is a Philip Morris USA Inc website, getiqos.com, rather than a regional variant of iqos.com as was the case in all other countries. This is because PM USA commercialises IQOS under a distribution agreement with PMI. ${ }^{32}$ In all countries, participants were asked to confirm they were over 18 years old (or 21 in the USA) to access the domestic IQOS website. Thirty-six participants across 17 countries (Austria, Colombia, Germany, Israel, Lebanon, Lithuania, Mexico, New Zealand, Poland, Republic of Korea, Spain, South Africa, Switzerland, Saudi Arabia, The Netherlands, Ukraine and the UK) were also asked to confirm they were current users of nicotine or tobacco (online supplemental table 2).

As shown in table 2, a wide variety of health-related claims were provided across the 54 successful webchat conversations. Fortyeight conversations (covering 20 countries) contained at least one claim that indicated IQOS is safer than cigarettes, of which 26 provided a quantitative value for the reduction in emission of harmful substances and 4 for the reduction of harm (tables 2 and 3). These included statements that harmful substances are reduced by 'an average of 95\%' (DE, PL, ZA, ES and $\mathrm{CH}$ ), ' $u p$ to 95\%' (AT, DK, MX and PL), 'about 97\%' (CH), 'on average over 95\%' (NZ), '90\%-95\%' (DK and GB), '80\%' (IT) and '95\%' (AT, BG, $\mathrm{LB}, \mathrm{MX}, \mathrm{CH}, \mathrm{SA}$ and $\mathrm{GB}$ ), or that IQOS reduces harm and risk to health by "95\%" (AT, CO and MX). In two conversations in Germany and one each in Austria and Poland, operators explained the percentage reduction in harmful substances was based on the 'the average reduction of the concentration of individual harmful substances according to the WHO standard'.

Of the six conversations that did not contain claims suggesting IQOS is safer than cigarettes, one was in Lebanon in which the participant was referred to the PMI Science website for more information. One in The Netherlands and one in the USA explained that IQOS is not risk free. In all three Lithuanian conversations, participants were told 'Unfortunately, for legal reasons, we are unable to answer your question on this platform'.

There were three conversations (two in Lithuania and one in Lebanon) in which participants did not ask about the relative 
Table 1 Total completed participant forms from each country

\begin{tabular}{|c|c|c|c|c|c|}
\hline Country (ISO $\alpha-2$ code) & Total participant forms & There was no webchat & Failed webchat* & Successful webchat & Language used in successful webchat \\
\hline Armenia (AM) & 1 & 1 & - & - & N/A \\
\hline Austria (AT) & 2 & - & - & 2 & German, $n=2$ \\
\hline Bulgaria (BG) & 2 & - & - & 2 & Bulgarian, $n=2$ \\
\hline Canada (CA) & 3 & - & 2 & 1 & English, $\mathrm{n}=1$ \\
\hline Colombia (CO) & 2 & - & - & 2 & Spanish, $n=2$ \\
\hline Denmark (DK) & 3 & - & - & 3 & $\begin{array}{l}\text { Danish, } \mathrm{n}=1 \\
\text { English, } \mathrm{n}=2\end{array}$ \\
\hline France (FR) & 3 & - & 2 & 1 & French, $n=1$ \\
\hline Germany (DE) & 2 & - & - & 2 & German, $n=2$ \\
\hline Greece (GR) & 3 & - & - & 3 & Greek, $n=3$ \\
\hline Israel (IL) & 3 & 3 & - & - & $\mathrm{N} / \mathrm{A}$ \\
\hline Italy (IT) & 3 & - & - & 3 & $\begin{array}{l}\text { English, } n=1 \\
\text { Italian, } n=2\end{array}$ \\
\hline Lebanon (LB) & 3 & - & - & 3 & $\begin{array}{l}\text { Arabic, } n=1 \\
\text { English, } n=2\end{array}$ \\
\hline Lithuania (LT) & 3 & - & - & 3 & $\begin{array}{l}\text { English, } n=1 \\
\text { Lithuanian, } n=2\end{array}$ \\
\hline Mexico (MX) & 3 & - & - & 3 & Spanish, $n=3$ \\
\hline New Zealand (NZ) & 3 & - & - & 3 & English, $n=3$ \\
\hline Poland (PL) & 3 & - & - & 3 & $\begin{array}{l}\text { English, } n=1 \\
\text { Polish, } n=2\end{array}$ \\
\hline Republic of Korea (KR) & 1 & - & 1 & - & N/A \\
\hline Saudi Arabia (SA) & 2 & - & - & 2 & Arabic, $n=2$ \\
\hline Serbia (RS) & 3 & 3 & - & - & $\mathrm{N} / \mathrm{A}$ \\
\hline Slovenia (SI) & 3 & - & - & 3 & Slovenian, $n=3$ \\
\hline South Africa (ZA) & 3 & - & - & 3 & English, $n=3$ \\
\hline Spain (ES) & 2 & - & - & 2 & Spanish, $n=2$ \\
\hline Switzerland (CH) & 3 & - & - & 3 & $\begin{array}{l}\text { German, } n=1 \\
\text { French, } n=2\end{array}$ \\
\hline The Netherlands (NL) & 3 & - & - & 3 & $\begin{array}{l}\text { English, } n=1 \\
\text { Dutch, } n=2\end{array}$ \\
\hline Ukraine (UA) & 3 & 3 & - & - & N/A \\
\hline United Kingdom (UK) & 3 & - & - & 3 & English, $n=3$ \\
\hline $\begin{array}{l}\text { United States of America } \\
\text { (US) }\end{array}$ & 2 & 1 & - & 1 & English, $n=1$ \\
\hline Total & 70 & 11 & 5 & 54 & \\
\hline
\end{tabular}

*Failed webchat refers to collected forms in which a webchat conversation was attempted but ceased before any relevant information could be collected.

safety of IQOS and e-cigarettes, likely due to the aforementioned responses when inquiring about IQOS and cigarettes. Two conversations in Mexico, one in Germany and one in New Zealand stated IQOS is safer than e-cigarettes (table 2), but no operators quantified their relative safety. In the remaining conversations, operators did not indicate whether IQOS is safer than e-cigarettes. Instead, they typically explained that IQOS is not an e-cigarette, stated information on their relative safety was not available and/or repeated claims on the relative safety of IQOS and cigarettes. In one webchat in Italy, an operator ended the conversation immediately after being asked about IQOS and e-cigarettes. In one webchat in Lithuania, the participant was again told 'Unfortunately, for legal reasons, we are unable to answer your question on this platform'.

The July 2020 US FDA MRTP decision regarding IQOS $^{6}$ was referenced in one conversation in Greece and two in South Africa. Participants in 19 conversations were referred to other IQOS web pages or PMI websites (pmi.com or pmiscience.com) for further information on the health effects of IQOS and accompanying science (AT, BG, CO, DK, GR, LB, LT, MX, NZ, ZA, ES, CH and $\mathrm{UK})$ (online supplemental table 3 ). In eight conversations, participants were told research on whether IQOS is a reduced risk product is ongoing (CO, DK, SI, NZ and PL) and that definitive conclusions on its reduced risk status cannot currently be made (SI and PL). Yet, IQOS was called a 'reduced risk [product/device]' in five other conversations (CA, IT, MX, NZ and PL).

\section{DISCUSSION}

Seventy data collection attempts were recorded in 27 of the 57 target countries. Of these, 54 successful webchat conversations were recorded across 22 countries. The majority included claims indicating IQOS is safer than cigarettes but did not comment on the relative safety of IQOS and e-cigarettes. The one conversation in Lebanon and one in The Netherlands in which operators did not comment on the relative safety of IQOS and cigarettes are outliers both across all countries covered and across all conversations collected within those countries. The reason for these outlying responses is unclear; there does not appear to be any local regulation prohibiting tobacco harm reduction claims in either country. At the time, claims regarding the lack of burning and reduced harmful substances were permitted in IQOS marketing in the USA, ${ }^{6}$ yet in the single USA conversation collected, no such claims were made. It is possible marketing materials and operator training were in the 
Table 2 Health-related claims collected from IQOS webchat conversations

\begin{tabular}{|c|c|c|}
\hline & Conversations, $\mathrm{n}(\%)^{*}$ & Examples \\
\hline \multicolumn{3}{|c|}{ Claims indicating IQOS is safer than cigarettes } \\
\hline $\begin{array}{l}\text { IQOS reduces harm or risk } \\
\text { compared with cigarettes }\end{array}$ & $28(52)$ & $\begin{array}{l}\text { 'IQOS is a reduced risk product'. (CA1, IT2, NZ1, PL2) } \\
\text { 'Switching completely from cigarettes to IQOS presents less risk to your health than continuing to smoke'. (CO1) } \\
\text { 'IQOS is less harmful and a better alternative from cigarettes'. (LB1) }\end{array}$ \\
\hline $\begin{array}{l}\text { IQOS emits less harmful } \\
\text { substances compared with } \\
\text { cigarettes }\end{array}$ & $36(67)$ & $\begin{array}{l}\text { 'The aerosol contains significantly lower levels of harmful chemicals than cigarette smoke'. (UK3) } \\
\text { 'It contains } 95 \% \text { less chemicals than regular cigarettes'. (LB3) }\end{array}$ \\
\hline $\begin{array}{l}\text { IQOS heats not burns tobacco } \\
\text { or is smoke-free }\end{array}$ & $45(83)$ & $\begin{array}{l}\text { 'IQOS heats tobacco rather than burning it'. (DK3, NZ2) } \\
\text { 'As there is no combustion, there is no tar, no smoke, no ash and less smell!'. (UK1, UK3) }\end{array}$ \\
\hline $\begin{array}{l}\text { IQOS has no negative impact on } \\
\text { indoor air quality }\end{array}$ & $2(4)$ & $\begin{array}{l}\text { 'IQOS has no negative impact on indoor air quality'. (ZA3) } \\
\text { 'IQOS has no impact on air quality'. (CO1) }\end{array}$ \\
\hline $\begin{array}{l}\text { IQOS does not stain teeth or } \\
\text { skin }\end{array}$ & $2(4)$ & $\begin{array}{l}\text { 'The yellow teeth and the ashes are not produced'. (AT1) } \\
\text { 'Avoiding stains on tongue teeth lips fingers nails'. (MX2) }\end{array}$ \\
\hline $\begin{array}{l}\text { IQOS does not cause passive } \\
\text { smoking }\end{array}$ & $2(4)$ & $\begin{array}{l}\text { 'There is no passive smoking with IQOS'. (FR3) } \\
\text { 'Moreover will not cause passive smoking'. (CH3) }\end{array}$ \\
\hline \multicolumn{3}{|c|}{ Claims including a quantitative value for the relative safety of IQOS and cigarettes } \\
\hline $\begin{array}{l}\text { IQOS emits X\% less harmful } \\
\text { substances }\end{array}$ & $26(48) \dagger$ & $\begin{array}{l}\text { 'Up to } 95 \% \text { less harmful substances'. (BG2, PL1) } \\
\text { 'On average over } 95 \% \text { lower levels of harmful chemicals'. (NZ2) } \\
\text { 'About } 97 \% \text { less harmful products'. (CH1) }\end{array}$ \\
\hline IQOS is X\% less harmful & $4(7) \dagger$ & $\begin{array}{l}\text { 'IQOS is } 95 \% \text { less harmful compared to normal cigarettes'. (AT2) } \\
\text { 'It avoids } 95 \% \text { the risk to your health'. (MX2) }\end{array}$ \\
\hline \multicolumn{3}{|c|}{ Claims indicating IQOS is safer than e-cigarettes } \\
\hline IQOS is safer than e-cigarettes & $4(7)$ & $\begin{array}{l}\text { 'So we're not allowed to give a real recommendation, but rather IQOS than e-cigarettes, the liquid is first of all } \\
\text { liquid and I have also heard that it sticks in your lungs'. (DE1) } \\
\text { 'It is safer compare to other e-cigarettes'. (NZ2) } \\
\text { 'It is much safer than a cigarette and a vape'. (MX3) } \\
\text { 'Participant: So you can say that IQOS is safer than vaping, right? IQOS Support: Yes'. (MX1) }\end{array}$ \\
\hline \multicolumn{3}{|l|}{ Other claims } \\
\hline IQOS produces less/no odour & $21(39)$ & $\begin{array}{l}\text { 'It does not leave that smell on your hands or clothes'. (CO2) } \\
\text { 'Less odor is emitted'. (BG2) }\end{array}$ \\
\hline IQOS is not risk free & $37(69)$ & $\begin{array}{l}\text { 'IQOS is by no means harmless or without risk'. (AT1, DE1) } \\
\text { 'IQOS is not risk free'. (DK3, NZ1, NZ3) }\end{array}$ \\
\hline IQOS is not a cessation device & $7(13)$ & $\begin{array}{l}\text { 'IQOS is not for quitting'. (AT1) } \\
\text { 'IQOS is not an alternative to quitting'. (DK3) } \\
\text { 'IQOS is not a cessation device'. (US1) }\end{array}$ \\
\hline $\begin{array}{l}\text { Reduced exposure does not } \\
\text { equal reduced risk }\end{array}$ & $6(11)$ & $\begin{array}{l}\text { 'IQOS sticks releases } 95 \% \text { less harmful substances in compared to cigarettes, but this does not necessarily amount } \\
\text { to a } 95 \% \text { reduction in risk'. (BG2) }\end{array}$ \\
\hline
\end{tabular}

*Percentage of the 54 successful webchat conversations.

†1 conversation in Colombia contained both \% less harmful substances and \% less harmful.

process of being updated to comply with the new MRTP authorisation. In Lithuania, all direct and indirect advertising of tobacco is banned, ${ }^{33}$ which may explain why all responses in Lithuania were 'Unfortunately, for legal reasons, we are unable to answer your question here'.

There is no conclusive evidence to suggest IQOS is safer than e-cigarettes, ${ }^{24-29}$ which may explain the lack of comment on their relative safety in most conversations. Stating 'we're not allowed to give a real recommendation' and use of the singular form of the first person ('I have also heard') suggests the response in Germany indicating IQOS is safer than e-cigarettes may be the operator's personal opinion. Contrastingly, the two other statements on this issue, one each in Mexico and New Zealand, were more assertive, presented more like a fact than an individual opinion. In Mexico, PMI may be using this claim as part of its extensive campaigning in the region ${ }^{35}$ where, until recently, manufacturers used a legal loophole to market HTPs. ${ }^{36}$

Some statements, both within and between countries, were contradictory. For example, IQOS being called a 'reduced risk [device/product]' somewhat contradicting statements that research on its reduced risk status is ongoing, and claims that IQOS presents '95\% less risk to your health' or 'is $95 \%$ less harmful' contradicting statements that a $95 \%$ reduction in harmful substances does not equal a $95 \%$ reduction in risk. The adjustable order and wording of the pre-set questions could have influenced responses, especially in cases where questions were repeated, providing opportunity for further statements to be made. Differing regulation also likely contributes to betweencountry response variation.

Within-country variation is less simply explained. The contradictory quantitative statements on exposure and risk may be due to webchat operators confusing the reduction in harmful substances with risk reduction. This raises concern that reduced exposure and reduced harm claims can easily be conflated by IQOS webchat operators, in line with similar observations of conflation among potential consumers. ${ }^{9} 10$ The variation in the quantitative figures, like '95\%' versus '97\%' (Switzerland), and accompanying language, like 'about' versus 'on average over' (Switzerland), provided within the same country might be the result of human error on the part of the webchat operators. Alternatively, insufficient training on appropriate and consistent responses, as well as domestic regulation that less stringently controls health risk communications of tobacco products could also contribute to variation in responses within the same country. 
Table 3 Number of webchat conversations by country with statements regarding relative safety of IQOS versus other products

\begin{tabular}{|c|c|c|c|c|c|c|c|c|c|}
\hline \multirow[b]{2}{*}{$\begin{array}{l}\text { Country (number of } \\
\text { successful webchats) }\end{array}$} & \multicolumn{8}{|c|}{ IQOS and cigarettes } & \multirow{2}{*}{$\begin{array}{l}\text { IQOS and e- } \\
\text { cigarettes } \\
\text { IQOS is safer } \\
\text { than e- } \\
\text { cigarettes }\end{array}$} \\
\hline & $\begin{array}{l}\text { IQOS } \\
\text { reduces } \\
\text { harm or } \\
\text { risk }\end{array}$ & $\begin{array}{l}\text { IQOS emits } \\
\text { less harmful } \\
\text { substances }\end{array}$ & $\begin{array}{l}\text { IQOS heats not } \\
\text { burns tobacco } \\
\text { or is smoke } \\
\text { free }\end{array}$ & $\begin{array}{l}\text { IQOS has no } \\
\text { negative impact } \\
\text { on indoor air } \\
\text { quality }\end{array}$ & $\begin{array}{l}\text { IQOS does } \\
\text { not stain } \\
\text { teeth or skin }\end{array}$ & $\begin{array}{l}\text { IQOS does } \\
\text { not cause } \\
\text { passive } \\
\text { smoking }\end{array}$ & $\begin{array}{l}\% \text { less } \\
\text { harmful } \\
\text { substances }\end{array}$ & $\begin{array}{l}\% \text { less } \\
\text { harmful }\end{array}$ & \\
\hline Austria $(n=2)$ & 2 & 1 & 2 & - & 1 & - & 1 & 1 & - \\
\hline Bulgaria $(n=2)$ & 2 & 2 & 2 & - & - & - & 1 & - & - \\
\hline Canada $(\mathrm{n}=1)$ & 1 & - & 1 & - & - & - & - & - & - \\
\hline Colombia $(n=2)$ & 2 & 2 & 2 & 1 & - & - & $1^{*}$ & $1^{*}$ & - \\
\hline Denmark $(n=3)$ & - & 3 & 2 & - & - & - & 3 & - & - \\
\hline France $(n=1)$ & - & - & 1 & - & - & 1 & - & - & - \\
\hline Germany ( $n=2$ ) & 2 & 2 & 2 & - & - & - & 2 & - & 1 \\
\hline Greece $(n=3)$ & - & - & 3 & - & - & - & - & - & - \\
\hline Italy $(n=3)$ & 1 & 1 & 3 & - & - & - & 1 & - & - \\
\hline Lebanon $(n=3)$ & 2 & 2 & 1 & - & - & - & 2 & - & - \\
\hline Lithuania ( $n=3$ ) & - & - & - & - & - & - & - & - & - \\
\hline Mexico $(n=3)$ & 3 & 2 & 3 & - & 1 & - & 1 & 2 & 2 \\
\hline New Zealand $(n=3)$ & 1 & 2 & 3 & - & - & - & 1 & - & 1 \\
\hline Poland $(n=3)$ & 1 & 3 & 3 & - & - & - & 3 & - & - \\
\hline Saudi Arabia ( $n=2$ ) & 2 & 2 & 2 & - & - & - & 1 & - & - \\
\hline Slovenia $(n=3)$ & - & 1 & 3 & - & - & - & - & - & - \\
\hline South Africa ( $n=3$ ) & 1 & 3 & 3 & 1 & - & - & 3 & - & - \\
\hline Spain $(n=2)$ & 2 & 2 & 2 & - & - & - & 1 & - & - \\
\hline Switzerland $(n=3)$ & 2 & 3 & 2 & - & - & 1 & 3 & - & - \\
\hline The Netherlands $(n=3)$ & 2 & 2 & 2 & - & - & - & - & - & - \\
\hline UK $(n=3)$ & 2 & 3 & 3 & - & - & - & 2 & - & - \\
\hline USA $(n=1)$ & - & - & - & - & - & - & - & - & - \\
\hline Total, n (\%)† & $28(52)$ & $36(67)$ & $45(83)$ & $2(4)$ & $2(4)$ & $2(4)$ & $26(48)$ & $4(7)$ & $4(7)$ \\
\hline
\end{tabular}

* 1 conversation in Colombia contained both \% less harmful substances and \% less harmful.

tPercentage of the 54 successful webchats conversations.

Most participants were told IQOS is not risk free, which could help prevent misinterpretation of reduced risk claims as meaning IQOS is risk free. Nevertheless, the use of claims based on contentious science and conflation between reduced harmful substances and reduced risk to health documented in the webchat conversations may be considered somewhat misleading based on previous evidence. ${ }^{9-11}$ The WHO previously condemned British American Tobacco (BAT) for misleadingly associating WHO with BAT's HTP, Glo, by making similar statements to those identified in webchats in Germany, Austria and Poland regarding reduced emission of harmful substances. ${ }^{37}$ Misleading promotion of tobacco products appears to be prohibited in 17 of the 27 countries covered in this study. ${ }^{38-55}$

In the USA, the FDA stipulates that PMI (and PM USA) are not allowed to imply IQOS is FDA endorsed following its authorisation as a modified risk tobacco product in July $2020 .{ }^{6}$ In line with this, the FDA's ruling was not referenced in conversations in the USA, but it was referenced in Greece and South Africa consistent with observations of PMI's use of the decision in other countries. ${ }^{56}$ In Greece, citing the FDA decision is consistent with local regulation that allows the use of science-based reduced risk claims in HTP advertising. ${ }^{57}$ However, such allowances do not yet exist in South Africa, and at the time of writing this, there is currently regulatory turmoil in the region over a proposed bill that would more strictly regulate products like IQOS. ${ }^{58}$

Assessing the regulatory framework of tobacco-related online chats is challenging, not least because marketing restrictions on HTPs are variable across countries. Implementing and enforcing existing tobacco control regulations related to HTPs is difficult because the electronic devices (ie, IQOS) required to heat the tobacco sticks (ie, HEETS) are generally not covered under such regulations. HTPs may also fall outside the definition of 'tobacco products' within specific country regulations. ${ }^{21}$ Online consumer commercial communications, such as the IQOS webchats detailed here, likely fall within a comprehensive advertising ban as called for in the WHO Framework Convention on Tobacco Control Article $13^{59}$ and its guidelines ${ }^{60}$ but could also be covered under other areas of the law, such as consumer protection laws, non-tobacco advertising laws and privacy laws. Even if legislation perfectly addressed this form of commercial communication, regulators may lack capacity and resources to readily enforce restrictions, especially in regions where multiple private digital communication methods are employed, like text and social media messaging. Despite these challenges, regulators could conduct tests using similar methods to those in this study to determine whether the corporate communication conforms to regulation. Method of age verification and need for smoker status confirmation could also be investigated to ensure IQOS is only marketed to the appropriate audience.

\section{Strengths and limitations}

The small sample size (22 out of 57 target countries and 1-3 webchat attempts per country) limits the generalisability of our findings. The sample size was restricted due to using author networks to recruit participants. However, in using this 
participant base, we could simultaneously cover numerous countries without PMI becoming aware of the study, which could have influenced responses. Moreover, participants were more likely to have some prerequisite knowledge relevant to the study and able to read and write in English. While not mandatory, all participants provided their own translations. Proficiency in English was not verified, which increases the chance of translational errors. Nonetheless, the similarity in responses given within and across countries, and their similarity to claims frequently used in IQOS promotional materials, suggests translations were reasonably done. Finally, one author analysed webchat conversations due to their brevity and simplicity. Use of a second coder would have increased reliability of the analysis.

\section{CONCLUSION}

Notwithstanding its limitations, the design of this study and its findings offer some much-needed insight into the health risk communications used by PMI to promote IQOS in a previously unexplored webchat feature. These insights are especially pertinent as IQOS marketing increasingly uses online media and health-related claims, ${ }^{36162}$ particularly during the COVID-19 pandemic. ${ }^{6364}$ Statements made in the IQOS webchat generally indicated IQOS is safer than cigarettes but did not comment on its safety relative to e-cigarettes. The diverse range of claims used, instances of contradictory statements, within-country variation and inconsistent smoker status confirmation when accessing the IQOS online store highlight blind spots in existing regulation. Stronger and clearer regulation is needed to ensure corporate communication of the health risks of products like IQOS via live webchat services are accurate and only reach the appropriate audience.

\section{What this paper adds}

- Communication of the health risks of IQOS has contributed to its commercial success, but caution is needed to ensure it is accurate and only attracts smokers, not non-smokers.

- The growing use of digital marketing methods, such as live webchat services, presents new challenges to tobacco control regulation.

- Across most countries covered in this study webchat responses indicated IQOS is safer than cigarettes but did not comment on the relative safety of IQOS and e-cigarettes.

- Instances of varying or contradicting statements between countries were likely due to differing domestic regulation, but within-country response variation is less easily explained.

- Tobacco or nicotine use status of potential consumers was not required consistently across all countries or within some countries.

- Regulators should explore appropriate regulations to control tobacco product marketing using webchat services and the communication of health risks of products like IQOS.

\section{Twitter J Robert Branston @JRBranston}

Acknowledgements The authors wish to thank those who participated in the data collection. We would also like to thank Monique E Muggli, Associate Legal Director in the International Programme at the Campaign for Tobacco-Free Kids, for her input on the regulatory context relevant to this study.

Contributors SB, AG and JRB conceived the study idea and developed the study design. SB conducted the survey and analysis. SB drafted the manuscript, which was edited and reviewed by all authors. SB accepts full responsibility for the finished work and the conduct of the study, had access to the data and controlled the decision to publish.

Funding We acknowledge the support of Bloomberg Philanthropies' Stopping Tobacco Organisations and Products funding (http://www.bloomberg.org/).
Disclaimer The funders had no role in the study design, data collection and analysis, decision to publish or preparation of the manuscript.

Competing interests JRB owns 10 shares in Imperial Brands for research purposes. The shares were a gift from a public health campaigner and are not held for financial gain or benefit. All dividends received are donated to health-related charities, and proceeds from any future share sale or takeover will be similarly donated. SB and AG declare no competing interests.

Patient consent for publication Not applicable.

Ethics approval This study involves human participants and was approved by The Research Ethics Approval Committee for Health, University of Bath, UK (EP 19/20 058). Participants gave informed consent to participate in the study before taking part.

Provenance and peer review Not commissioned; externally peer reviewed.

Data availability statement Data are available on reasonable request. Deidentified data may be requested by researchers from the corresponding author.

Open access This is an open access article distributed in accordance with the Creative Commons Attribution Non Commercial (CC BY-NC 4.0) license, which permits others to distribute, remix, adapt, build upon this work non-commercially, and license their derivative works on different terms, provided the original work is properly cited, appropriate credit is given, any changes made indicated, and the use is non-commercial. See: http://creativecommons.org/licenses/by-nc/4.0/.

\section{ORCID iDs}

Sophie Braznell http://orcid.org/0000-0001-7443-2795

J Robert Branston http://orcid.org/0000-0002-2332-2403

\section{REFERENCES}

1 Tobacco Tactics. Next generation products: Philip Morris international 2021. Available: https://tobaccotactics.org/wiki/next-generation-products-philip-morris-international/ [Accessed 16 Mar 2021].

2 Philip Morris International. Philip Morris international 2020 annual report 2020. Available: https://philipmorrisinternational.gcs-web.com/static-files/9f1f0ec5-f5ec4164-93ee-8057210a8205 [Accessed 14 Jul 2021].

3 Jackler R, Ramamurthi D, Axelrod A. Global Marketing of IQOS. The Philip Morris Campaign to Popularize "Heat Not Burn" Tobacco, 2020. Available: http://tobacco. stanford.edu/tobacco_main/publications/IQOS_Paper_2-21-2020F.pdf [Accessed 16 Mar 2021].

4 Bialous SA, Glantz SA. Heated tobacco products: another tobacco industry global strategy to slow progress in tobacco control. Tob Control 2018;27:s111-7.

5 Elias J, Dutra LM, St Helen G, et al. Revolution or redux? Assessing IQOS through a precursor product. Tob Control 2018;27:s102-10.

6 US Food and Drug Administration. FDA Authorizes Marketing of IQOS Tobacco Heating System with 'Reduced Exposure' Information 2020. Available: https://www. fda.gov/news-events/press-announcements/fda-authorizes-marketing-iqos-tobaccoheating-system-reduced-exposure-information [Accessed 16 Mar 2021].

7 Tompkins CNE, Burnley A, McNeill A, et al. Factors that influence smokers' and exsmokers' use of IQOS: a qualitative study of IQOS users and ex-users in the UK. Tob Control 2021;30:16-23.

8 McKelvey K, Popova L, Kim M, et al. IQOS labelling will mislead consumers. Tob Control 2018;27:s48-54.

9 El-Toukhy S, Baig SA, Jeong M, et al. Impact of modified risk tobacco product claims on beliefs of US adults and adolescents. Tob Control 2018;27:s62-9.

10 Popova L, Lempert LK, Glantz SA. Light and mild redux: heated tobacco products' reduced exposure claims are likely to be misunderstood as reduced risk claims. Tob Control 2018;27:s87-95.

11 Wackowski OA, O'Connor RJ, Diaz D, et al. '95\% less harmful'? Exploring reactions to quantitative modified risk claims for snus and e-cigarettes. Tob Control 2021:tobaccocontrol-2020-056303.

12 Jankowski M, Brożek GM, Lawson J, et al. New ideas, old problems? Heated tobacco products - a systematic review. Int J Occup Med Environ Health 2019:32:595-634.

13 Simonavicius E, McNeill A, Shahab L, et al. Heat-not-burn tobacco products: a systematic literature review. Tob Control 2019;28:582-94.

14 US Food and Drug Administration. Scientific Review of Modified Risk Tobacco Product Application (MRTPA) Under Section 911(d) of the FD\&C Act -Technical Project Lead 2020. Available: https://www.fda.gov/media/139796/download [Accessed 16 Mar 2021].

15 Philip Morris International. Reduced risk products Briefing: Philip Morris international collection, Reuters, 2014. Available: https://www.industrydocuments.ucsf.edu/docs/\# id=tmpp0230 [Accessed 7 Jun 2021].

16 Bach L. Tobacco product marketing on the Internet 2021. Available: https://www. tobaccofreekids.org/assets/factsheets/0081.pdf [Accessed 14 Jul 2021].

17 Philip Morris International. IQOS 2021. Available: https://uk.iqos.com/ [Accessed 8 Ap 2021]. 
18 Weinberg BD, Parise S, Guinan PJ. Multichannel marketing: Mindset and program development. Bus Horiz 2007;50:385-94.

19 Comm 100. Live Chat benchmark report 2021, 2021. Available: https://www. comm100.com/resources/report/live-chat-benchmark-report/chats-per-month/ [Accessed 8 Oct 2021].

20 O'Brien EK, Navarro MA, Hoffman L. Mobile website characteristics of leading tobacco product brands: cigarettes, smokeless tobacco, e-cigarettes, hookah and cigars. Tob Control 2019;28:532-9.

21 Campaign for Tobacco-Free Kids. Heated tobacco products. global regulation 2020. Available: https://www.tobaccofreekids.org/assets/global/pdfs/en/HTP_regulation_en. pdf [Accessed 16 Mar 2021].

22 Freeman B. New media and tobacco control. Tob Control 2012;21:139-44.

23 Philip Morris International. Scientific update. Historic decision 2020. Available: https:// www.pmiscience.com/resources/docs/default-source/scientific-updates/pmi-scientificupdate-issue-11.pdf?sfvrsn=7cced106 10 [Accessed 16 Mar 2021].

24 Adriaens K, Gucht DV, Baeyens F. IQOS ${ }^{\overline{T M}}$ vs. e-Cigarette vs. Tobacco Cigarette: A Direct Comparison of Short-Term Effects after Overnight-Abstinence. Int J Environ Res Public Health 2018;15:2902.

25 Farsalinos KE, Yannovits N, Sarri T, et al. Carbonyl emissions from a novel heated tobacco product (IQOS): comparison with an e-cigarette and a tobacco cigarette. Addiction 2018;113:2099-106.

26 Leigh NJ, Palumbo MN, Marino AM, et al. Tobacco-specific nitrosamines (TSNA) in heated tobacco product IQOS. Tob Control 2018;27:s37-8.

27 Nga JDL, Hakim SL, Bilal S. Comparison of end tidal carbon monoxide levels between conventional cigarette, electronic cigarette and heated tobacco product among asiatic smokers. Subst Use Misuse 2020;55:1943-8.

28 Leigh NJ, Tran PL, O'Connor RJ, et al. Cytotoxic effects of heated tobacco products (HTP) on human bronchial epithelial cells. Tob Control 2018:27:s26-9.

29 Biondi-Zoccai G, Sciarretta S, Bullen C, et al. Acute Effects of Heat-Not-Burn, Electronic Vaping, and Traditional Tobacco Combustion Cigarettes: The Sapienza University of Rome-Vascular Assessment of Proatherosclerotic Effects of Smoking (SUR - VAPES) 2 Randomized Trial. J Am Heart Assoc 2019:8:e010455.

30 Philip Morris International. 2020 Second-Quarter results. Presentation slides 2020. Available: https://philipmorrisinternational.gcs-web.com/static-files/3246c242-ddf74ba3-90c9-323e9cfacb74 [Accessed 16 Mar 2021].

31 Disclosure and Barring Service. ISO country codes 2018. Available: https://www.gov. uk/government/publications/iso-country-codes-2 [Accessed 7 Apr 2021].

32 Altria Group. FDA Authorizes sale of IQOS tobacco heating system in the U.S. 2019. Available: https://www.businesswire.com/news/home/20190430006020/en/ [Accessed 8 Oct 2021]

33 Sytas A. Philip Morris may have breached Lithuania's advertising rules with new smoking device, 2018. Reuters. Available: https://www.reuters.com/article/us-tobaccoiqos-marketing-idUSKCN1G51SB [Accessed 16 Mar 2021].

34 The Tobacco Atlas. Lithuania 2021. Available: https://tobaccoatlas.org/country/ lithuania/ [Accessed 16 Mar 2021]

35 Cruz-Jiménez L, Barrientos-Gutiérrez I, Coutiño-Escamilla L, et al. Adult Smokers' Awareness and Interest in Trying Heated Tobacco Products: Perspectives from Mexico, where HTPs and E-Cigarettes are Banned. Int J Environ Res Public Health 2020;17:2173

36 TobaccoReporter. Heated tobacco exempted from ban 2021. Available: https:// tobaccoreporter.com/2021/07/23/heating-products-exempted-from-mexico-ends-ban/ [Accessed 11 Oct 2021].

37 World Health Organization. WHO condemns misleading use of its name in marketing of heated tobacco products 2018. Available: https://web.archive.org/web/ 20210328170204/https://www.who.int/tobacco/communications/statements/namemarketing-tobacco/en/ [Accessed 28 Mar 2021].

38 Campaign for Tobacco-Free Kids. Legislation by country: Armenia. Regulated forms of advertising, promotion and sponsorship, 2021. Available: https://www. tobaccocontrollaws.org/legislation/country/armenia/aps-regulated-forms [Accessed 10 Mar 2021].

39 Campaign for Tobacco-Free Kids. Legislation by country: Canada. Regulated forms of advertising, promotion and sponsorship, 2021. Available: https://www. tobaccocontrollaws.org/legislation/country/canada/aps-regulated-forms [Accessed 10 Mar 2021].

40 Campaign for Tobacco-Free Kids. Legislation by country: Colombia. Regulated forms of advertising, promotion and sponsorship 2020. Available: https://www. tobaccocontrollaws.org/legislation/country/colombia/aps-regulated-forms [Accessed 10 Mar 2021].

41 Campaign for Tobacco-Free Kids. Legislation by country: France. Regulated forms of advertising, promotion and sponsorship 2019. Available: https://www. tobaccocontrollaws.org/legislation/country/france/aps-regulated-forms [Accessed 10 Mar 2021].

42 Campaign for Tobacco-Free Kids. Legislation by country: Germany. Regulated forms of advertising, promotion and sponsorship 2019. Available: https://www. tobaccocontrollaws.org/legislation/country/germany/aps-regulated-forms [Accessed 10 Mar 2021]

43 Campaign for Tobacco-Free Kids. Legislation by country: Italy. Regulated forms of advertising, promotion and sponsorship 2020. Available: https://www. tobaccocontrollaws.org/legislation/country/italy/aps-regulated-forms [Accessed 10 Mar 2021].

44 Campaign for Tobacco-Free Kids. Legislation by country: Lebanon. Regulated forms of advertising, promotion and sponsorship 2019. Available: https://www. tobaccocontrollaws.org/legislation/country/lebanon/aps-regulated-forms [Accessed 16 Mar 2021].

45 Campaign for Tobacco-Free Kids. Legislation by country: Mexico. Regulated forms of advertising, promotion and sponsorship 2020. Available: https://www. tobaccocontrollaws.org/legislation/country/mexico/aps-regulated-forms [Accessed 16 Mar 2021].

46 Campaign for Tobacco-Free Kids.. Legislation by country: new Zealand. Regulated forms of advertising, promotion and sponsorship 2020. Available: https://www. tobaccocontrollaws.org/legislation/country/new-zealand/aps-regulated-forms [Accessed 16 Mar 2021].

47 Campaign for Tobacco-Free Kids. Legislation by country: Poland. Regulated forms of advertising, promotion and sponsorship 2019. Available: https://www. tobaccocontrollaws.org/legislation/country/poland/aps-regulated-forms [Accessed 16 Mar 2021].

48 Campaign for Tobacco-Free Kids. Legislation by country: Saudi Arabia. Regulated forms of advertising, promotion and sponsorship 2020. Available: https://www. tobaccocontrollaws.org/legislation/country/saudi-arabia/aps-regulated-forms [Accessed 16 Mar 2021].

49 Campaign for Tobacco-Free Kids. Legislation by country: Slovenia. Regulated forms of advertising, promotion and sponsorship 2020. Available: https://www. tobaccocontrollaws.org/legislation/country/slovenia/aps-regulated-forms [Accessed 16 Mar 2021]

50 Campaign for Tobacco-Free Kids. Legislation by country: South Africa. Regulated forms of advertising, promotion and sponsorship 2019. Available: https://www. tobaccocontrollaws.org/legislation/country/south-africa/aps-regulated-forms [Accessed 16 Mar 2021].

51 Campaign for Tobacco-Free Kids. Legislation by country: Spain. Regulated forms of advertising, promotion and sponsorship 2019. Available: https://www. tobaccocontrollaws.org/legislation/country/spain/aps-regulated-forms [Accessed 16 Mar 2021].

52 Campaign for Tobacco-Free Kids. Legislation by country: Ukraine. Regulated forms of advertising, promotion and sponsorship 2019. Available: https://www. tobaccocontrollaws.org/legislation/country/ukraine/aps-regulated-forms [Accessed 16 Mar 2021].

53 Campaign for Tobacco-Free Kids. Legislation by country: England. Regulated forms of advertising, promotion and sponsorship 2020. Available: https://www. tobaccocontrollaws.org/legislation/country/england/aps-regulated-forms [Accessed 16 Mar 2021].

54 Campaign for Tobacco-Free Kids. Ordonnance sur les produits du tabac et les produits contenant des succédanés de tabac destinés être fumés (Ordonnance sur le tabac, OTab), 2004. Available: https://www.tobaccocontrollaws.org/files/live/Switzerland/ Switzerland\%20-\%200rdinance\%20on\%20Tobacco\%20-\%20national.pdf [Accessed 16 Mar 2021].

55 US Food and Drug Administration. Section 903 of the Federal Food, Drug, and Cosmetic Act - Misbranded Tobacco Products 2019. Available: https://www.fda.gov/ tobacco-products/rules-regulations-and-guidance/section-903-federal-food-drug-andcosmetic-act-misbranded-tobacco-products [Accessed 8 Oct 2021].

56 Tobacco Tactics. PMI promotion of IQOS using FDA MRTP order 2020. Available: https://tobaccotactics.org/wiki/pmi-iqos-fda-mrtp-order/ [Accessed 16 Mar 2021]

57 Tobaccolntelligence. Alternative tobacco and nicotine products in Greece 2021. Available: https://tobaccointelligence.com/geography/greece/ [Accessed $10 \mathrm{Mar}$ 2021]

58 Tobacco Tactics. South Africa: industry interference with the control of tobacco products and electronic delivery systems bill 2020. Available: https://tobaccotactics. org/wiki/south-africa-industry-interference-with-the-control-of-tobacco-products-andelectronic-delivery-systems-bill/ [Accessed 16 Mar 2021].

59 WHO Framework Convention on Tobacco Control. Articles 13(2), 13(4)(a) 2005 Available: https://apps.who.int/iris/bitstream/handle/10665/42811/9241591013.pdf; jsessionid=C2D9CFC5B7B4EF17156BB3A29E921369? sequence $=1$ [Accessed 7 Jun 2021].

60 Conference of the Parties (COP). Guidelines for implementation of article 13 of the WHO framework convention on tobacco control (tobacco advertising, promotion and sponsorship), 2008. Available: https://www.who.int/fctc/guidelines/article_13.pdf [Accessed 7 Jun 2021].

61 Dagli E, Guner M, Sonmez U. Heated tobacco product marketing: Internet platforms undermine regulations. Eur Respir J 2019:54:PA1693.

62 Evans-Reeves K, Gilmore A, Zatonski M. Addiction at any cost. Philip Morris international uncovered: stop, 2020. Available: https://exposetobacco.org/wp-content uploads/STOP_Report_Addiction-At-Any-Cost.pdf [Accessed 16 Mar 2021].

63 Campaign for Tobacco-Free Kids. Big tobacco is exploiting COVID-19 to market its harmful products, 2020. Available: https://www.tobaccofreekids.org/media/2020/ 2020_05_covid-marketing [Accessed 16 Mar 2021].

64 OCCRP. Pandering to a pandemic, 2020. Available: https://www.occrp.org/en/ loosetobacco/blowing-unsmoke/pandering-to-pandemic [Accessed 16 Mar 2021] 